\title{
PARAMETERIZATION OF CONVECTIVE CLOUDS, MESOSCALE CONVECTTVE SYSTEMS, AND CONVECTIVE-GENERATED CIRRUS
}

Your 2 Technical Progress Report for:

September 15, 1991 - September 14, 1992

Willam R. Cotton, Principal Investigator

Colorado State University

Dept. of Atmoopheric Saience

Fort Collins, CO 80523

March 3, 1992

Prepared for:

U.S. DEPARTMENT OF ENERGY

Atmospharic Radiation Meaurement Program

GRANT \#: DE-FG02-90ER61066 


\section{NOTICE}

This report was prepared as an account of work sponsored by the United States Government. Naither the United States nor the Departmeat of Energy, nor any of their employees, nor any of their contractors, sub-contractors, or their employees, makes any warranty, express of implied, or assumes any legal liability of responsibility for the accuracy, completeness, or usefulness of any information, apparatus, product or progress dloclosed or represents that is use would not infringe privately-owned rights. 


\section{Abstract}

A Level 2.5w deep convection updraft/downdraft parameterization scheme has been refined and tested against 3D simulations of sea-breeze generated convection over S. Florida. Cases for explicit simulation of MCSs in mid-latitudes and tropics have been selected. Pilot simulations of these cases with coarse horizontal resolution have been encouraging. After a few refinements in those cases, fine resolution explicit simulations of deep convection and mesoscale, stratiform clouds will be begun.

\section{Refinements in the deep convective parameterization scheme}

The scheme for parameterizing deep convective cloud updrafts and downdrafts developed by Weissbluth (1991) has been modified and refined.

First, the tendencies to the model variables are specified rather than the fluxes. Then, the cumulus forcing becomes

$$
\left(\frac{\partial \overline{\mathcal{X}}}{\partial t}\right)_{\text {cumulus }}=\sigma_{u, d}\left[w^{* * *} \frac{\partial \overline{\mathcal{X}}}{\partial z}+\frac{1}{\bar{T}}\left(\mathcal{X}_{u, d}-\overline{X_{e}}\right)\right],
$$

where $w^{* m}=\sqrt{w^{\prime} w^{\prime}}$. The second term on the rhs of Eq. 1 is the convective adjustment term where $T$ is the time scale over which convection modifies the environment. This time scale is determined frrm forcing the moist static energy of the convective tendencies to be zero, $i . e$.

$$
T=\frac{\int_{l c l}^{c t}\left[L\left(r_{o u}-\overline{r_{v}}\right)-L\left(r_{t u}-\overline{r_{t}}\right)+C_{p}\left(T_{u}-\bar{T}\right)\right] \rho d z}{\int_{l c l}^{c t} w^{* * t}\left[L \frac{\partial \overline{T_{t}}}{\partial z}-L \frac{\partial \overline{r_{u}}}{\partial z}-C_{p} \frac{\partial \bar{T}}{\partial z}\right] \rho d z} .
$$

There are several interpretations of Eq. 1 which can be made. When cumulus forcing is diagnosed, the first term on the rhs combines with the resolvable advection. Bougeault (1985) then interprets the first term on the rhs as a subsidence term since the resolvable vertical motion in large-scale models is negligible compared to $w^{* * *}$. The second term is then interpreted as the detrainment term. In large scale models, then, the subsidence term prompts warming and drying while the detrainment term prompts warming and moistening.

In mesoscale models, the resolved vertical motion may be comparable to $w^{* * *}$ and a different interpretation of the term is needed. In this case, the advection by the resolved motions and the first 
term on the rhs (now called the compensation term) combine to give near zero net advection which is desirable since the advection of the scalars is now being accomplished by the convective adjustment term. Double counting is then explicitly eliminated since the convective adjustment term wholly handles the updraft core warming and moistening. Furthermore, the continuous behavior of the compensation term as the grid size changes allows this parameterization scheme to be generally applicable on all grid resolutions.

In Eq. 1, either $w^{* *}$ or $T$ could be specified and the remaining coefficient determined from a moist static energy balance. Bougeault specified the convective flux as a function of height and diagnosed the detrainment time scale. We also feel that forcing $w^{* * *}$ to vary as $\sqrt{w^{\prime} w^{\prime}}$ is best since it allows a realistic vertical distribution of the compensation term which closely resembles the vertical distribution of the mean vertical motion. If the integral of the vertical gradient of moist static energy is negative, then this forces $T<0$. We disallow convection under this condition since a negative time scale for convection is clearly unrealistic. Presumably, explicit overturning will occur in the grid column when this condition appears, thus precluding the specification of parameterized convection.

\section{Testing the deep convective draft scheme}

We have also been performing some high resolution simulations of convective systems. Our grid spacing ( $1.5 \mathrm{~km}$ and $0.5 \mathrm{~km}$ on the finer nested grids) in these simulations is srnall enough to explicitly resolve convective scale features. This method allows us to create a synthetic data set for comparison with cumulus parameterization schemes.

Our first test case involves deep convection forced by sea breeze fronts along the Florida Peninsula. The specifics of this simulation are described in Hertenstein et al. (1991). Since then we have added one to three grids, each with the finest grid spacing used in this simulation, $0.5 \mathrm{~km}$. These are strategically placed within the domain to encompass a cloud during its entire life cycle. We can then conditionally sample the highly-resolved cloud to obtain information (e.g., condensate efficiency) which can then be spatially averaged and compared with the level $2.5 \mathrm{w}$ cumulus scheme. The use of this synthetic data set provides the best test for the parameterization since observations 
on such a fine scale do not exist. To capture the entire life cycle of the deeper convective cells in this simulation, we are testing the moving grid capability of RAMS. This allows us to keep our finest grid as small as possible, thereby saving computer resources.

\section{Selecting cases for explicit simulation of MCSs}

In order to develop a parameterization scheme of mesoscale convective systems, we plan to explicitly simulate both the deep convection and mesoscale motions in several mesoscale convective systems.

Our approach is to select several cases from the 1985 PRE-STORM experiment and one or more tropical cases from EMEX and/or Dundee. Then we perform test simulations of the cases using relatively coarse resolution $(\Delta x=\Delta y=25$ to $80 \mathrm{~km})$ using one of the cumulus parameterization scheme options available in RAMS. If the results of the coarse resolution runs look promising, then we plan to nest down to grid spacing of the order of 1.5 to $2 \mathrm{~km}$.

Thus far we have tested three cases. The first case tested during PRE-STORM is the 3-4 June 1985 episode of four MCSs (Fortune, 1989; Fortune et al., 1992). We have run this case with $\sim 80 \mathrm{~km}$ grid spacing using the Kuo and Weissbluth's level $2.5 \mathrm{w}$ cumulus parameterization scheme. Weissbluth's scheme seems to do the best so far, capturing all or part of the four systems. Further experimentation is planned, however, before we launch into the explicit convection simulation.

Our second test case involves the simulation of the 10-11 June 1985 PRE-STORM squall line. This case has been documented by observational as well as modeling studies, enabling us to do a thorough verification of the model results. This system was characterized by a well developed convective line and stratiform precipitating regions. We have completed initial coarse grid (80 km grid spacing) and have started adding finer grids. Our aim is to nest down to a fine resolution (on the order of $1 \mathrm{~km}$ ) centered on the stratiform precipitation area. We can then perform the same diagnostics as were done with the Florida Peninsula experiment; however these will apply to the less intensely precipitating stratiform region.

The third case is the mesoscale convective system observed during the ninth flight mission during the Equatorial Mesoscale Experiment (EMEX 9). Figs. 1 through 3 provide an overview 
of EMEX 9's development. Fig. 1 shows EMEX 9 near its inception - 1530 UTC (0130 LST) 2 February 1987. Fig. 2 shows the well-developed system at 2030 UTC (0630 LST). Fig. 3 shows EMEX 9 in its decaying stages at 0230 UTC (1230 LST).

The initial data are gridded data from an Australian Bureau of Meteorology Research Center (BMRC) objective analysis scheme. The BMRC scheme incorporates temperature and wind data from normal sounding stations supplemented by a special sounding network as well as data retrieved from satellites. The analysis yielded a set of synoptic data fields with 1.25 degree horizontal resolution, 11 level vertical resolution, and 6 hour temporal resolution for the entire EMEX period. The analysis spans from the equator to $30 \mathrm{~S}$ and from 110 .

A pilot simulation with a horizontal grid spacing of $40 \mathrm{~km}$ and a vertical grid spacing which varied from 500 to $1000 \mathrm{~m}$ has been performed. The domain was a box of $1600 \mathrm{~km}$ on each side, centered at $10 \mathrm{~S}$ and $139 \mathrm{E}$.

The simulation began with data from the 1100 UTC 2 February analysis and ended 9 hours later (so it did not span the entire life cycle of EMEX 9). Figs. 4,5, and 6, which show the accumulated convective precipitation after 3,6 , and 9 hours, respectively, shows that RAMS did produce an area of convective precipitation over the same area as EMEX 9 and was able to do it at about the right time. The simulation was far from perfect though - the simulated orientation of the convection is nore WNW to ESE rather than observed west-east orientation and extends too far to the northwest.

There are at least a few reasons why the model's simulation is not completely faithful to reality. First, surface data from the BMRC analysis have not been incorporated into RAMS. Second, we do not have any initial SST data yet (specified a constant SST). Third, the domain size was probably too small - the simulated convective system is nearly as wide as the domain itself. Whether correcting these problems will make any difference remains to be seen. 


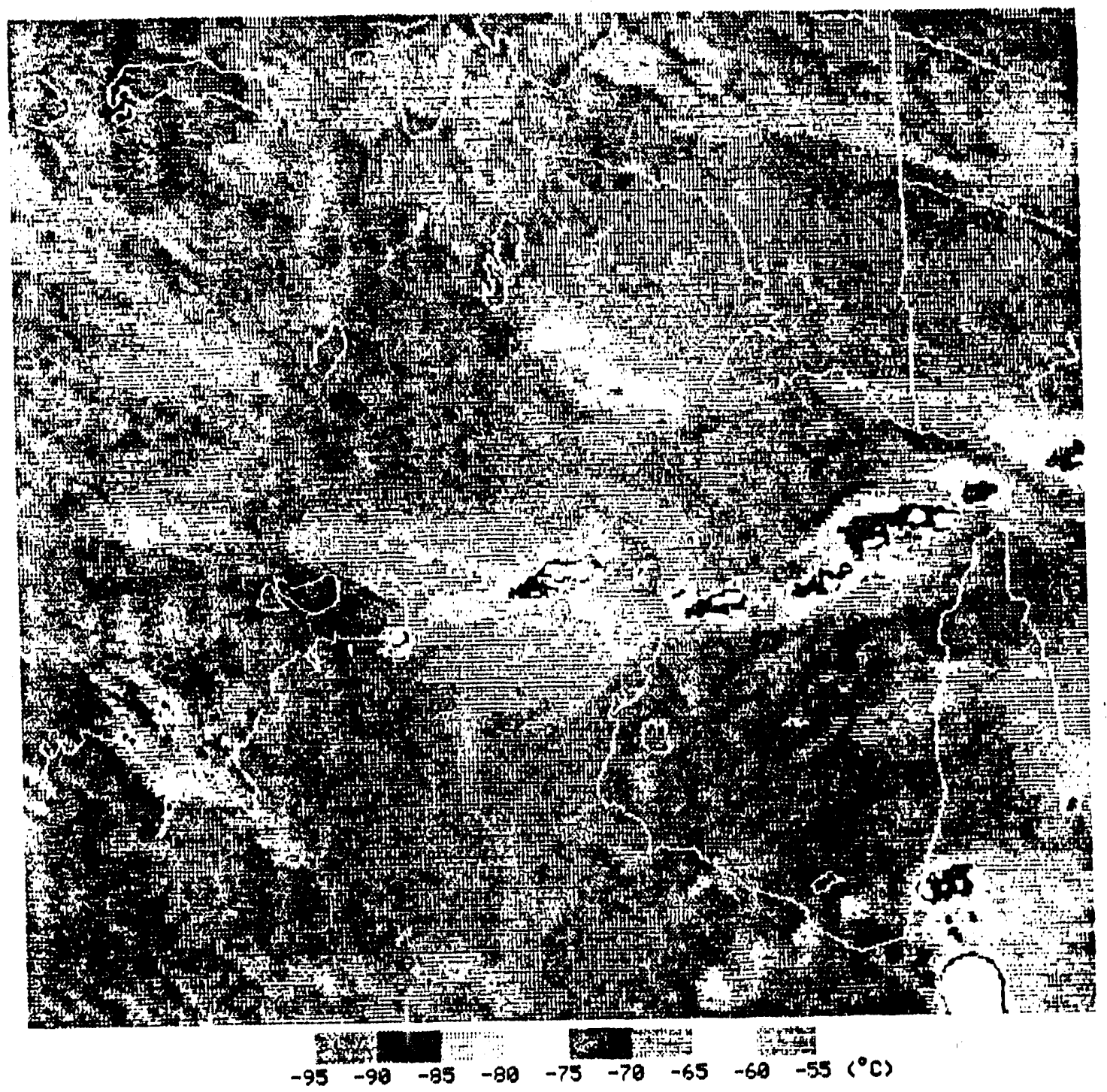

Figure 1: Infrared satellite image at 1530 UTC on 2 February 1987 over the EMEX region. 


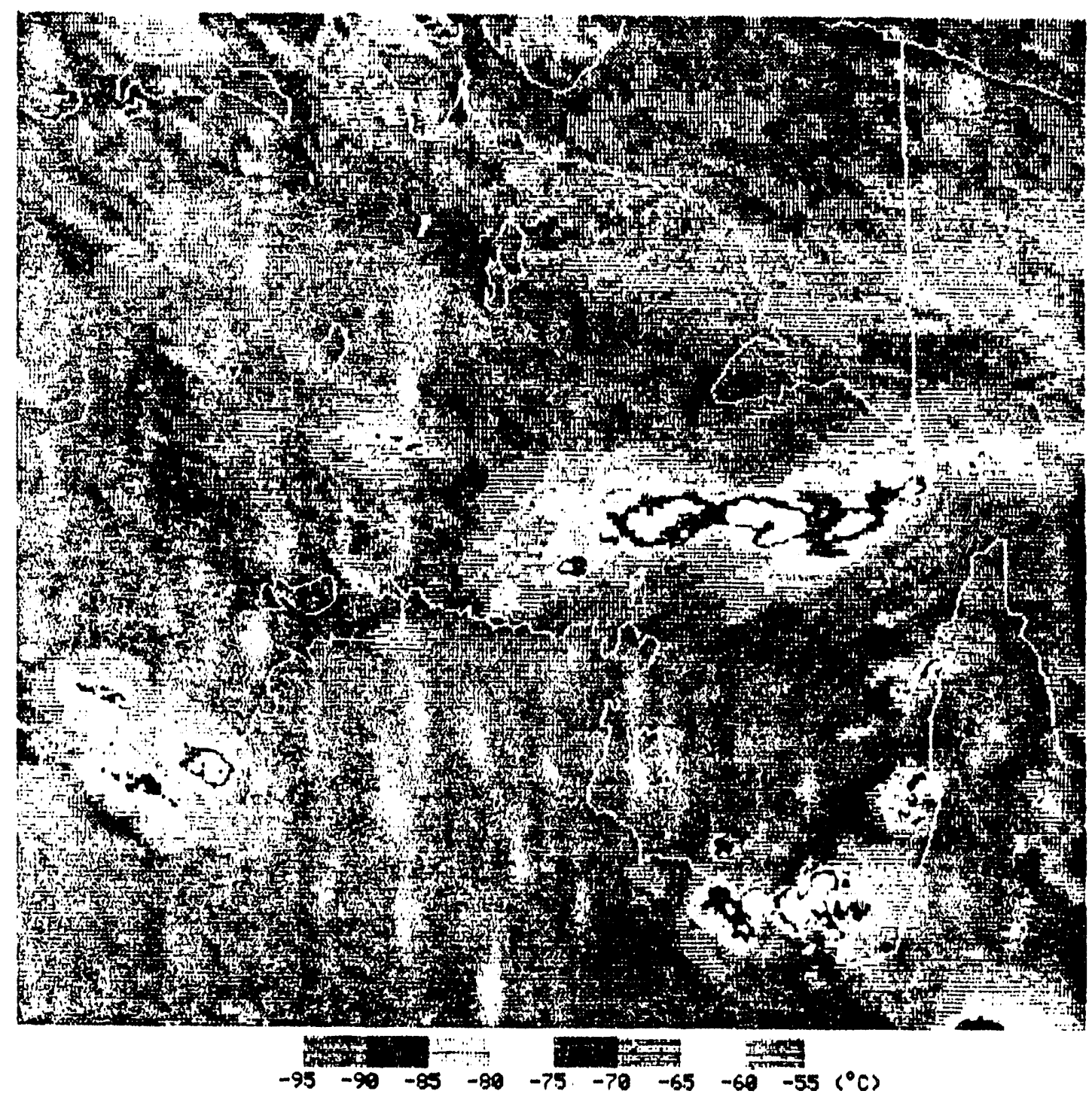

Figure 2: Same as Fig. 1 but for 2030 UTC. 


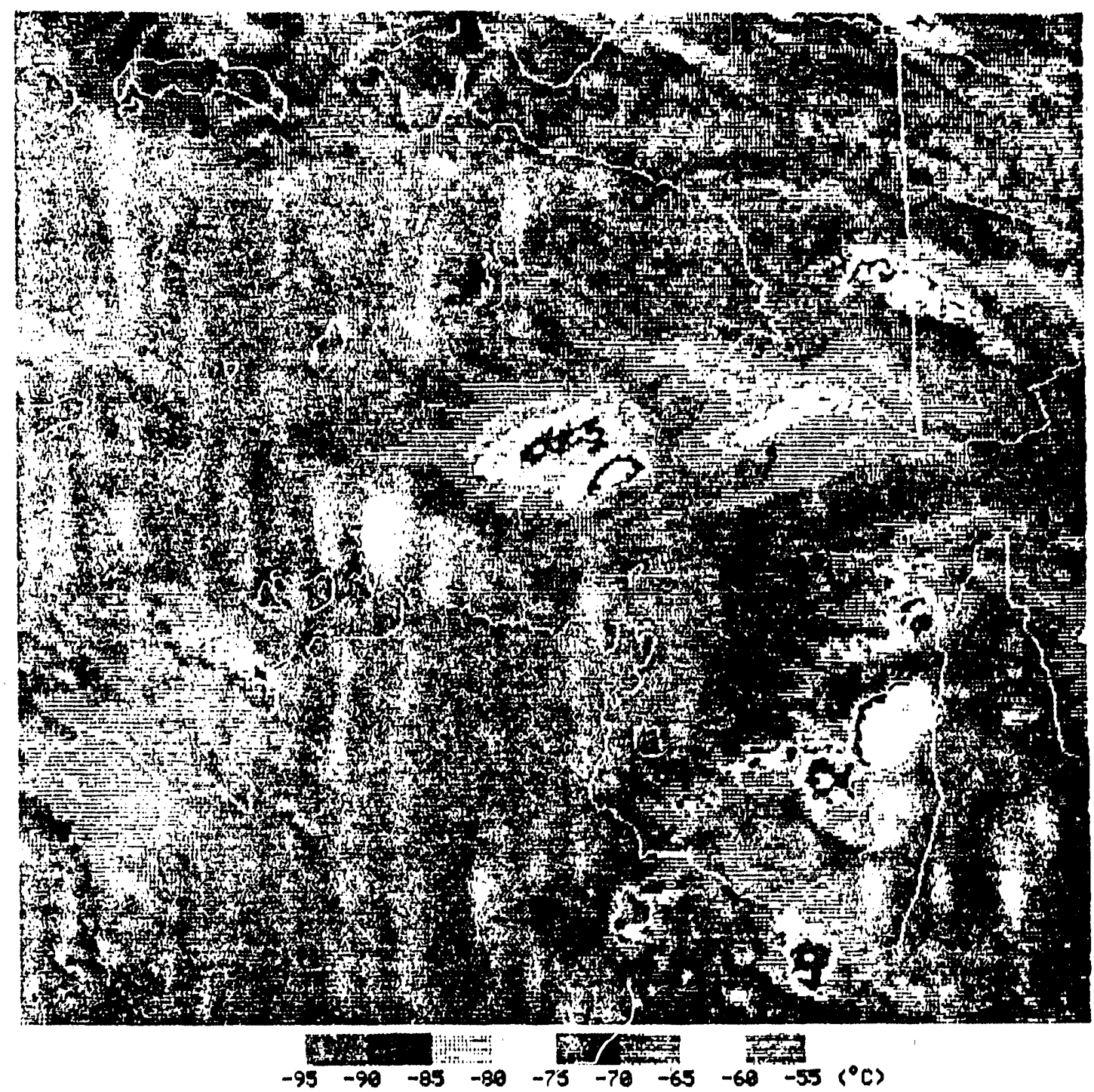

Figure 3: Same as Fig. 1 but for 2030 UTC on 3 February 1987. 
EMEX 9 Test Simulation

Grid 1

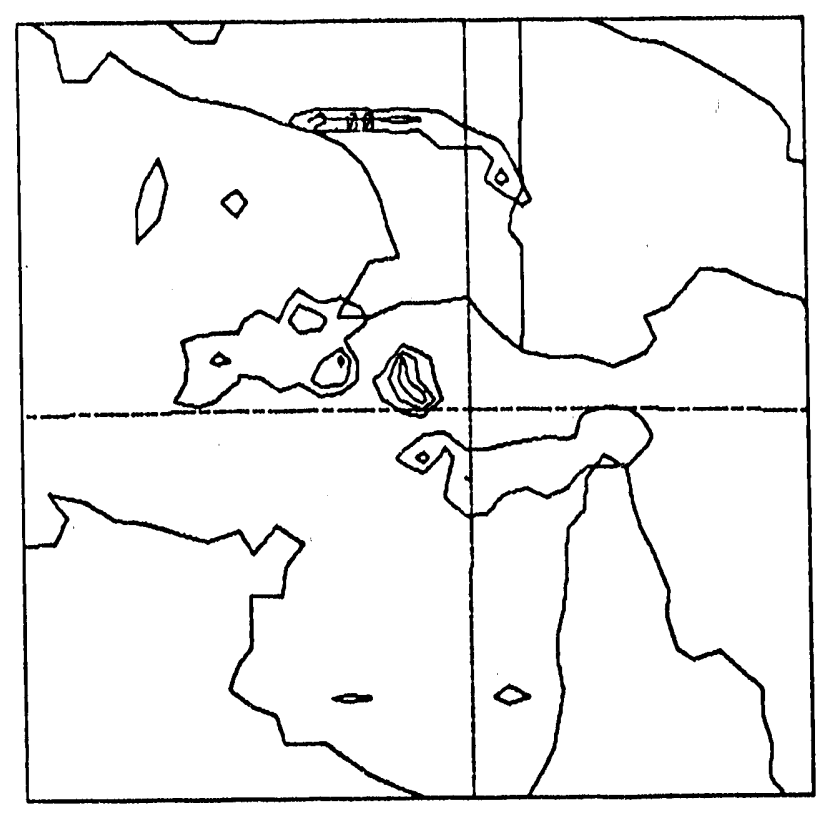

accum conv $P C P$
$z=-241.0 \mathrm{~m} \quad t=10800 . \mathrm{s}$

Figure 4: Accumulated convective precipitation after 3 hours of a RAMS simulation begun at 1200 UTC on 2 February 1987. 


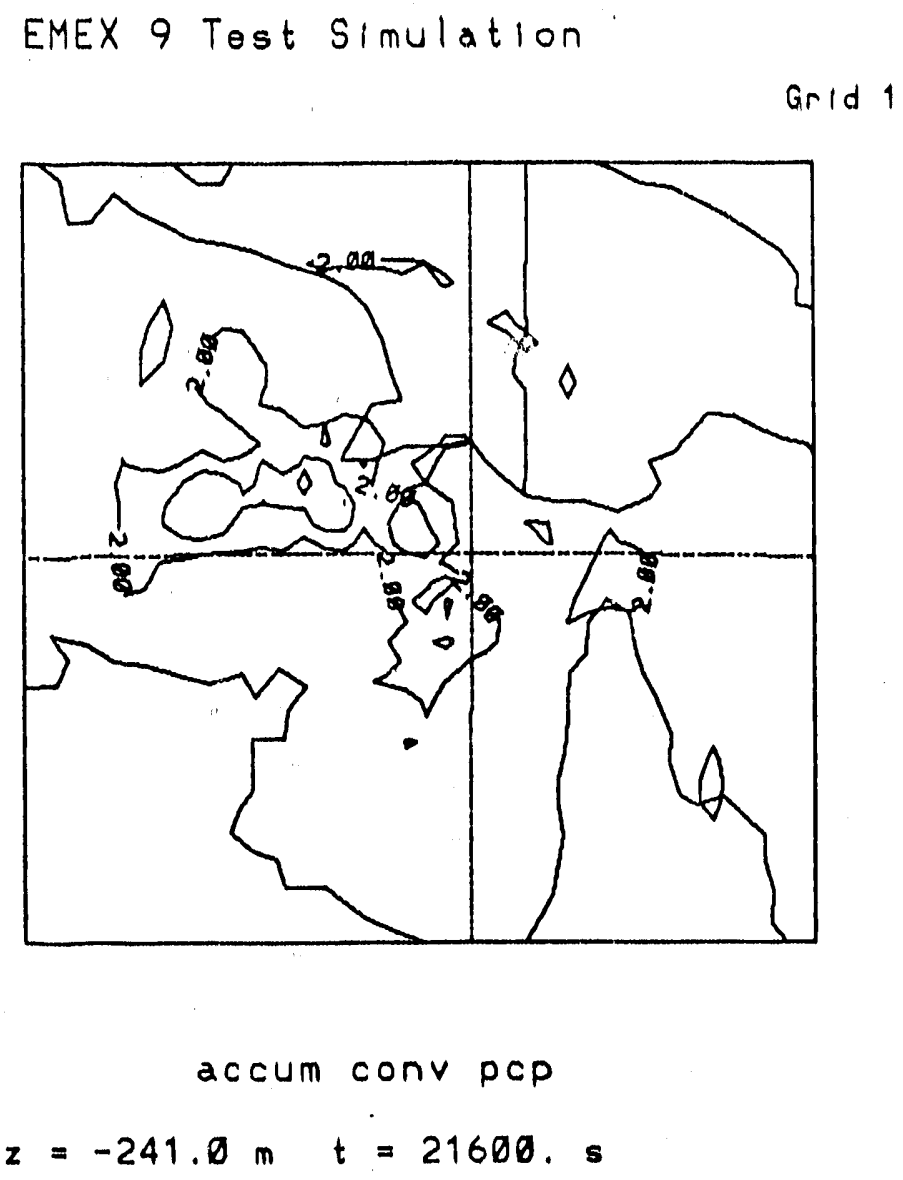

Figure 5: Same as Fig. 4 but after 6 hours. 


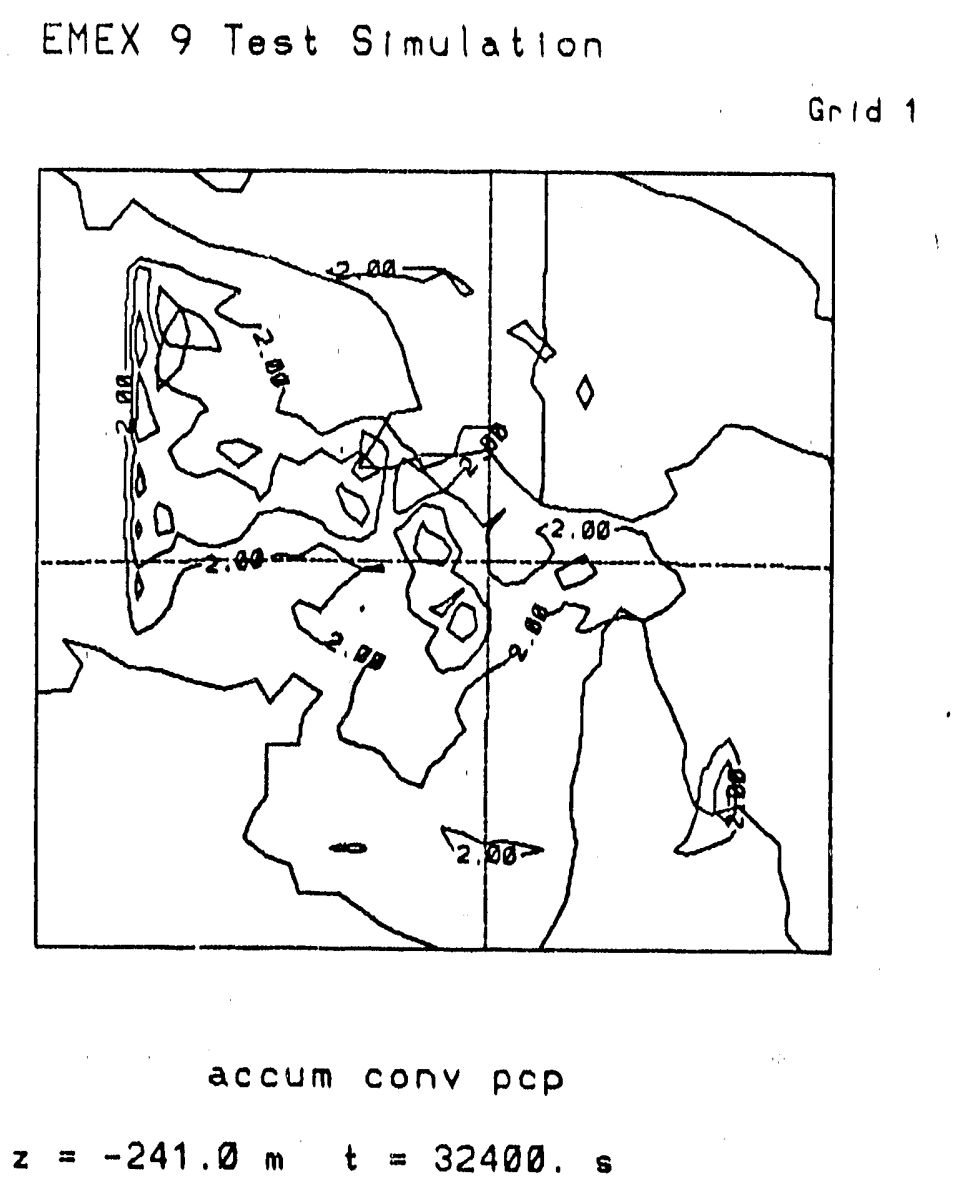

Figure 6: Same as Fig. 4 but after 9 hours. 


\section{References}

Bougeault, P., 1985: A simple parameterization of the large-scale effects of cumulus convection. Mon. Wea. Rev., 113, 2108-2121.

Fortune, Michael A., 1989: The evolution of vortical patterns and vortices in mesoscale convective complexes. Ph.D. Thesis, Colorado State University, Dept. of Atmospheric Science, Fort Collins, CO 80523.

Fortuze, M.A., W.R. Cotton, and R.A. McAnelly, 1992: Frontal wave-like evolution in some mesoscale convective complexes. Part I: The episode of June 3,4, 1985 Accepted Mon. Wea. Rev.

Hertenstein, R.F.A., W.R. Cotton, and M.J. Weissbluth, 1992: Quasi-three-dimensional simulations of deep convection. Freprints, 5th Conf. on Mesoscale Processes, Jan. 6-10, 1992, Atlanta, GA, Amer. Met. Soc.

Weissbluth, M.J., 1991: Convective parameterization in mesoscale models. Ph.D. Dissertation, Atmos. Sci. Yaper No. 486, Colnrado State University, Dept. of Atmospheric Science, Fort Collins, CO 80523, $211 \mathrm{pp}$.

\section{Publications supported}

Hertenstein, R.F.A., W.R. Cotton, and M.J. Weissbluth, 1992: Quasi-three-dimensional simulations of deep convection. Preprints, 5th Conf. on Mesoscale Processes, Jan. 6-10, 1992, Atlanta, GA, Amer. Met. Soc.

Randall, D.A., and D.-M. Pan., 1992: Implementation of the Arakawa-Schubert parameterization with a prognostic closure. To appear in Cumulus Parameterization, Meteorological Monograph, American Meteorological Society, K. Emanuel and D. Raymond, Eds. 
Weissbluth, M.J., and W.R. Cotton, 1991: A cumulus parameterization scheme designed for nested grid meso- $\beta$ scale models. Preprints, 9th Conf. on Numerical Weather Prediction, 14-18 Oct 1991, Denver, CO., Amer. Met. Soc.

Weissbluth, M.J., and W.R. Cotton, 1992: An approach for parameterining mesoscale precipitating systems. Preprints, 5th Conf. on Mesoscale Processes, Jan. 6-10, 1992, Atlanta, GA, Amer. Met. Soc.

Weissbluth, M.J., and W.R. Cotton, 1992: The representation of convection in mesoscale models. Part I: Scheme fabrication and calibration. Submitted to Mon. Wea. Rev. 

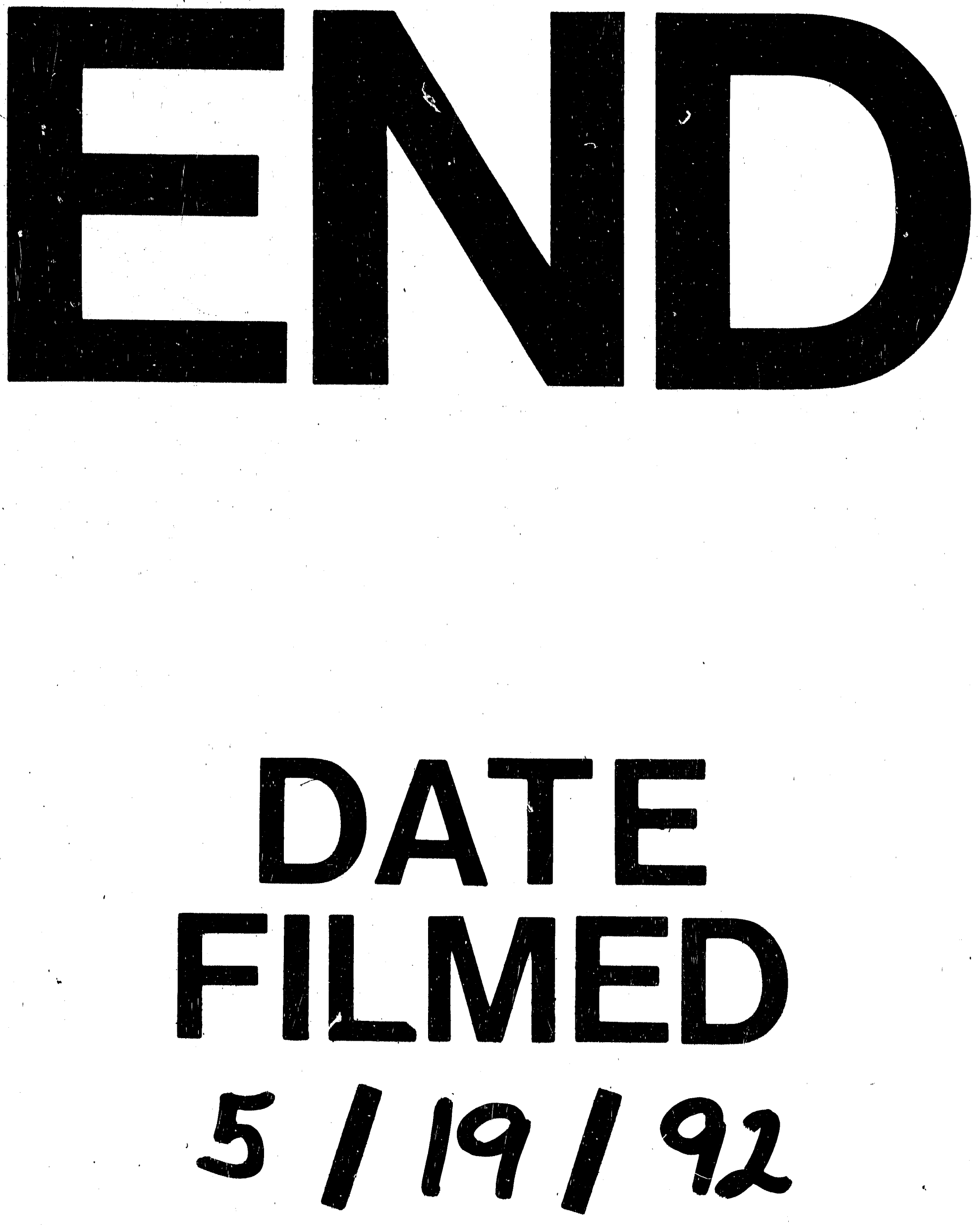
